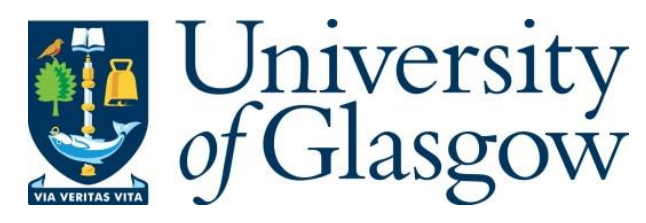

Palczynski, L.J., Bleach, E.C.L., Brennan, M.L. and Robinson, P. (2020) Giving calves 'the best start': perceptions of colostrum management on dairy farms in England. Animal Welfare, 29(1), pp. 45-58. (doi:10.7120/09627286.29.1.045)

There may be differences between this version and the published version. You are advised to consult the publisher's version if you wish to cite from it.

http://eprints.gla.ac.uk/209811/

Deposited on: 11 February 2020

Enlighten - Research publications by members of the University of Glasgow http://eprints.gla.ac.uk 


\section{Giving calves "the best start": Perceptions of colostrum management on dairy farms in England}

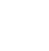

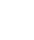

1

\section{Abstract}

15

Good colostrum management can confer protective immunity to newborn calves, making calves less susceptible to infectious disease, and fundamentally improving both their short- and longterm health, welfare and productivity. Industry recommendations commonly refer to 'The Three 'Q's' of colostrum management: the need for calves to receive sufficient 'Quantity' of high 'Quality' colostrum 'Quickly' after birth; some also include 'sQueaky clean' and 'Quantification of passive transfer'. However, research to date suggests that the failure of passive transfer of colostral antibodies is common on commercial dairy farms, contributing to suboptimal calf health and mortality. This paper explores why this may be the case by investigating stakeholder perceptions of colostrum management and how these perceptions might affect the practice of ensuring adequate colostrum administration to newborn calves. lpalczynski@harper-adams.ac.uk $+44(0) 1952820280$ 
Calf rearing and youngstock management practices on English dairy farms were investigated using 40 in-depth semi-structured interviews: 26 with dairy farmers and 14 with advisors (including veterinarians, feed and pharmaceutical company representatives). Interviews were audio recorded, transcribed and thematically coded for analysis. 'The Three 'Q's' were found to act as useful reminders about the goals of colostrum management, and a case can be made for further publicising the inclusion of 'sQueaky clean' and 'Quantification of passive transfer' as there remains a lack of focus on colostrum hygiene and measurement of successful antibody transfer. Knowledge of the 'Q's did not guarantee implementation, and time and labour constraints alongside farmer misconceptions must be addressed when offering professional advice on improving calf health. Further research to encourage on-farm collection and analysis of monitoring data including rates of passive transfer is particularly needed. Advisors must not overlook the importance of colostrum management when assessing farm practices and ensure that they promote evidence-based recommendations if dairy calf morbidity and mortality is to be reduced.

\section{$41 \quad$ Keywords}

Animal welfare; colostrum; dairy calf welfare; dairy calf health; qualitative research; stakeholder perceptions

\section{Introduction}

The ingestion of colostrum is of great importance to bovine neonates as it provides nutritive and non-nutritive components that influence the development of the gastrointestinal tract and the nutritional, metabolic and immune status of calves (Blum 2003). Of particular importance are the high levels of immunoglobulin (mainly $\mathrm{IgG}$ ) in colostrum (Godden 2008). Calves are born agammaglobulinemic so depend on the absorption of maternal colostral immunoglobulins through the wall of the small intestine in the first 24 hours of life (Weaver et al 2000; Godden 2008). Failure of passive transfer from colostrum is diagnosed when calf serum levels of $\operatorname{IgG}$ or 
total protein are less than $10 \mathrm{~g} / \mathrm{L}$ or $50 \mathrm{~g} / \mathrm{L}$, respectively (Patel et al 2014). Failure of passive transfer increases calves' susceptibility to infectious disease and mortality (Wittum \& Perino 1995; Raboisson et al 2016), reduces growth rates (Robison et al 1988), and has been linked to lower milk yield during their first lactation (DeNise et al 1989). The total cost related to failure of passive transfer has been estimated as $€ 60$ per calf in European dairy systems, including costs related to mortality, morbidity and reduced average daily weight gain (Raboisson et al 2016).

Current industry recommendations for colostrum management to promote successful passive transfer are based around principles commonly referred to as 'The Three 'Q's': 'Quantity', 'Quickly' and 'Quality' (Patel et al 2014; AHDB Dairy 2018). Calves should consume a volume of colostrum equating to at least 10\% of their bodyweight (3-4 L for a 30-40 kg calf) (Godden 2008). It is a legal requirement in England for calves to receive colostrum within six hours of birth (The Welfare of Farmed Animals (England) Regulations 2007 (as amended)); after six hours there is a progressive decline in the efficiency of immunoglobulin transfer across the gut epithelium until full gut closure at 24 hours of age (Godden 2008; Hart 2016). Calves should be artificially fed via nipple bottle or oesophageal tube due to concerns about the ability to attain sufficient immunoglobulin mass when suckling from the dam (McGuirk \& Collins 2004; Patel et al 2014). Immunoglobulin content of colostrum can be indirectly assessed using a colostrometer or Brix refractometer which measure specific gravity and total solids, respectively. Good quality colostrum contains over $50 \mathrm{~g} / \mathrm{L}$ of immunoglobulin which equates to $>22 \%$ (Brix) (Bartier et al 2015). Samples with readings below $20 \mathrm{~g} / \mathrm{L}$ or $22 \%$ (Brix) should be discarded (AHDB Dairy 2018). Concentrations of immunoglobulin in colostrum have been shown to decline rapidly over time from calving (Moore 2005) therefore colostrum should be harvested within six hours of parturition (Godden 2008). Pooling colostrum from multiple dams is not recommended; immunoglobulin content can be diluted (Weaver et al 2000), and disease risk may be increased (Godden 2008). 
Some extend recommendations from three to five 'Q's by including 'sQueaky clean' and

81 'Quantifying passive transfer' (Hart 2016). Bacterial contamination of colostrum interferes with absorption of immunoglobulins (Godden 2008) and total bacterial numbers and faecal coliform counts should not exceed 1000000 and $10000 \mathrm{cfu} / \mathrm{mL}$, respectively (McGuirk \& Collins 2004). Colostrum should be collected hygienically and either fed or refrigerated within one hour of milking to impede rapid multiplication of microorganisms. Batch-pasteurisation of colostrum eliminates or at least significantly reduces pathogens, including Mycobacterium avium subspecies paratuberculosis which causes Johne's disease (paratuberculosis) in cattle (Godden 2008). Johne's disease can be spread from infected adult cattle to calves through ingestion of faecal matter or contaminated colostrum, and is a key reason to implement 'snatch calving' where calves are immediately removed from their dam and fed either colostrum from Johne's test-negative cows (Windsor \& Whittington 2010) or colostrum replacement products (Godden 2008). Herd-based assessment of passive transfer, for example by monitoring serum total protein in healthy calves or zinc sulphate turbidity testing, can be used to evaluate colostrum management practices (McGuirk \& Collins 2004; Hart 2016). Where high rates of failure of passive transfer are evident, colostrum protocols are more likely to be reviewed and improved (Atkinson et al 2017; Sumner et al 2018).

97

It was first reported over 90 years ago that ingestion of colostrum confers protective immunity to newborn calves (Smith \& Little 1922), yet problems achieving adequate passive transfer from colostrum remain evident at farm level. Failure of passive transfer was estimated to occur in demonstrated that colostrum management remains poor on many farms (Kehoe et al 2007; Vasseur et al 2010a; Morrill et al 2012) suggesting that the scientific recommendations outlined above have failed to stimulate uptake of best practice by farmers. This could be because 
have conveyed the information to farmers but did not motivate them to make improvements to their colostrum management. In either case, it is very important to understand why recommendations are not implemented on farms. Farmer attitudes, such as perceived control

111 and ability to make decisions and take action towards improving calf health, have been shown

112 to influence husbandry practices related to calf mortality (Vaarst \& Sørensen 2009; Santman-

113 Berends et al 2014). Where the alteration of management practices is considered unnecessary, 114 impractical or unlikely to yield beneficial results, inaction is likely. On the other hand, positive 115 beliefs about the potential for improvement, and the ease of implementation, are more likely to 116 result in actions contributing to better calf management (Vaarst \& Sørensen 2009; Santman117 Berends et al 2014).

119 Although farmers have a vital primary role, it is likely that both farmer and advisor perspectives 120 and their interactions influence colostrum management on farms. For example, in response to benchmarking reports which included comparative passive transfer rates, many farmers consulted their veterinarian on how to make specific changes to improve their colostrum management (Atkinson et al 2017). However, in general practice, data relating to calf health are under-recorded on dairy farms (Bach \& Ahedo 2008), and farmers may believe that they have sufficient knowledge about calf rearing and the causes of problems on their farms, whereas veterinarians might consider those farmers' knowledge lacking, or inaccurate, in those areas, as was demonstrated in a Dutch study by Santman-Berends et al (2014). In such cases, farmers are unlikely to consult their veterinarians about calf health or performance issues, but veterinariandriven conversations explaining why certain practices could lead to problems and discussing possible improvements may convince farmers to take action (Santman-Berends et al 2014). On the other hand, it is possible that neither the farmer nor veterinarian is focused on the calf rearing enterprise (Sumner \& von Keyserlingk 2018), meaning colostrum management would be rarely discussed. Farmers may also receive input from other agricultural advisors with

134 different areas of expertise and focus compared to veterinarians (Ellingsen et al 2012), such as animal nutritionists and sales representatives from the pharmaceutical industry. Thus, exploring 
the perceptions of a range of stakeholders with regards to management of colostrum on dairy

137 farms will yield further useful insights. This paper therefore investigates farmer and farm-

138 advisor perceptions of colostrum management and administration to calves on dairy farms, to

139 better understand why uptake of recommendations for best practice may or may not occur.

140 Accepting the premise that if dairy calf health is generally suboptimal it may not be solely the

141 fault of farmers, this paper takes a wider perspective on the problem.

\section{Materials and methods}

143 Qualitative research methodologies from the social sciences are increasingly used to investigate

144 animal health and welfare issues from the perspectives of both veterinarians and farmers (eg

145 Robinson \& Epperson 2013; Brennan et al 2016; Bourély et al 2018; Robinson 2019) and

146 several authors have advocated such interdisciplinary approaches (eg Whay 2007; Escobar \&

147 Buller 2014). Qualitative methods are particularly useful to gain insight into choices made in relation to individual contexts, perspectives, emotions and priorities (Escobar \& Buller 2014).The current study utilises a critical realist paradigm which combines realist ontology (there is a real world which exists independently of our interactions with it) with constructivist epistemology (knowledge of the world is imperfect and subjective, influenced by human perceptions and concepts, resulting in different yet equally valid experiences and interpretations of reality). This means that perceptions and physical entities are considered equally important in understanding phenomena (Maxwell 2012) such as colostrum management on dairy farms. Whereas quantitative research counts occurrences, (eg which practices occur in a representative sample of farmers), the aim of this qualitative study is to describe a range of experiences and beliefs held by farmers and farm advisors which may contribute to choices and actions made regarding colostrum protocols on farms.

It is important to note the potential influence of the first author who conducted the face-to-face interviews, transcriptions and data analyses. Well recognised within the social sciences, qualitative research requires a reflexivity which considers the potential influence of the 
researcher, those interviewed, and the context within which the interviews take place (Rose 1997). The researcher embarked on the project from a background in animal health and welfare, without in-depth knowledge of the dairy industry, and was interested to gain insight into human influences on animal husbandry. The participants were considered 'experts' in rearing dairy calves, while the researcher positioned herself as curious to learn about the industry and individual practices on farms.

\section{Participants}

Calf rearing and youngstock management practices on English dairy farms were investigated using 40 in-depth semi-structured interviews - 26 with dairy farmers and 14 with advisors (veterinarians $(\mathrm{n}=11)$, feed $(\mathrm{n}=2)$ and pharmaceutical company representatives $(\mathrm{n}=1))$ conducted by the first author between May 2016 and June 2017. Advisors were included since they are often responsible for providing information to farmers, thus it was considered useful to compare their perceptions with those of farmers. Participants were recruited using purposive and snowball sampling (Cohen et al 2007) which involved approaching relevant individuals at dairy events and conferences; email and phone call enquiries with existing contacts and veterinary practices; and asking interviewees to provide details of others who may be interested in participating in the study. This method provided access to a range of farmers; both males and females with different roles on farms (farm managers, herd managers, calf rearers and farm workers) and with various dairy herd sizes and calf rearing systems (Table 1). Advisors willing to be interviewed tended to be those with a specific interest in dairy youngstock and included both males and females with a range in years of experience. For logistical reasons, interviews were conducted in batches according to geographical location. Participants were sourced from areas of England densely populated with dairy farms (Southwest and Midlands) and from a north-eastern area where dairy farms were less dense (Yorkshire). This sample diversity supported the aims of the study to examine how differing experiences affect perspectives and actions relating to calf management. 
Table 1. Interview participant details.

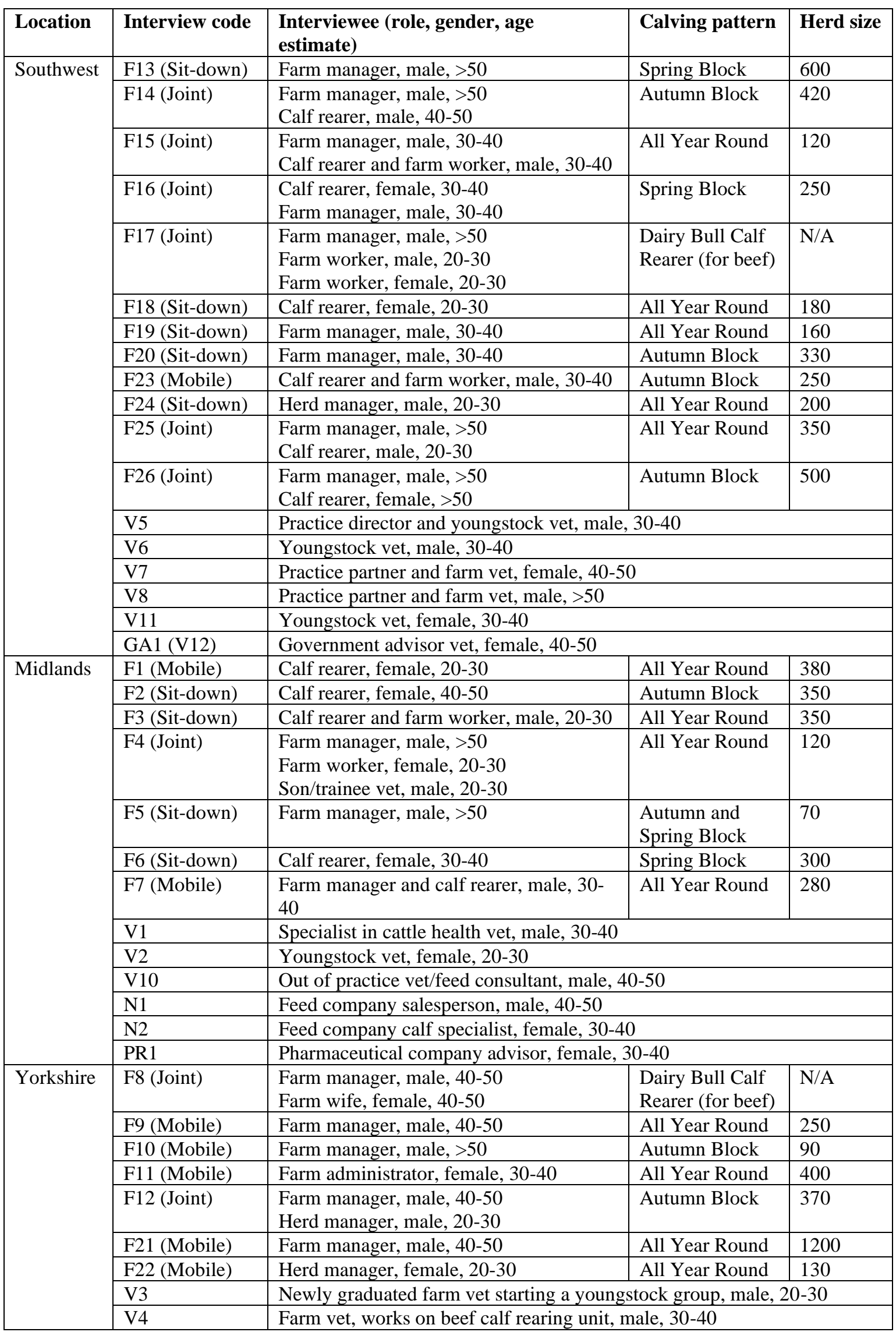


194 The semi-structured interviews followed two separate topic guides, one for farmer interviews and the other for advisor interviews. These included questions about the background of the interviewee, their current role and their opinions on the most important aspects of calf rearing. The farmers were asked about their farm, calf rearing practices and facilities, as well as problems, desired improvements and useful sources of information. Advisors were asked questions relating to their input into the calf rearing enterprise of their clients' farms, and how they thought farmers interacted with information and advice. These guides were designed to include open-ended questions which ensured conversations remained relevant to calf rearing yet allowed flexibility to explore issues of most importance to participants (Turner 2010) rather than being rigidly pre-determined by the interviewer. Advisors $(n=14)$ and some farmers $(n=$ 9) were interviewed in an individual, sit-down format; other farmers participated in mobile interviews $(n=8)$ where questions were posed whilst on a walking tour of the farm (Holton \& Riley 2014), or in joint interviews involving more than one interviewee ( $\mathrm{n}=20$ (9 interviews)) (Riley 2014). These interview formats were decided by the participants according to their personal preferences.

210 Due to the broad nature of the topic guide, specific questions pertaining to colostrum management were not included, rather it was mentioned by participants in response to questions including: 'What are the most important things to get right in calf rearing?'; 'What do you think might not be done well on farms?' and 'How are calves managed from birth to weaning?'. Data collection and analysis were conducted concurrently in an iterative process whereby topics raised by participants could be incorporated into and explored further through ongoing interviews (Glaser \& Strauss 1967) to gain further data richness (Bradley et al 2007). The structure, prompts and areas of focus varied between interviews depending on what participants were most willing to talk about in detail, and which topics emerged from initial ongoing data analysis in order to further explore areas of interest, importance or contention. Seven pilot interviews were conducted (four with farmers, two veterinarians and one feed company 
representative) to ensure the interview guides were suitable. Since only minor refinements were made to the guides after these interviews, and responses were relevant and useful to the research project, the pilot interviews were included in the overall dataset. Data collection ceased when thematic saturation (the point at which the main ideas and variations relevant to the topic have been identified) had been achieved (Glaser \& Strauss 1967).

Interviews were audio recorded with consent and subsequently manually transcribed in full using f4transkript transcription software (Version 6.2.5 Edu, Audiotranskription.de, Marburg, Germany).

\section{Data analysis}

232 NVivo 11 for Windows qualitative data analysis software (Version 11.4.1.1064 Pro, QSR International Pty Ltd, Victoria, Australia) was used to aid thematic coding of the interview transcripts which involved re-reading the data and grouping extracts to be interpreted into themes (Braun \& Clarke 2006).

First and second coding principles (Miles et al 2014) were used. Transcripts were initially coded in NVivo, assigning descriptive codes to arrange extracts into common topics, value codes to reflect personal factors such as attitudes, beliefs and feelings, and process coding to highlight actions and consequences (Miles et al 2014). These initial codes informed ongoing interviews and provided a basis for focal topics - such as colostrum management. Second cycle coding was conducted to further examine specific extracts relating to colostrum management, constructing patterns, themes and potential explanations. This involved focused coding using NVivo 11 followed by physically arranging individual extracts into common themes and choosing quotes to include in this paper. Quotes were chosen which clearly represented opinions and experiences of participants. Some quotes were modified to shorten or improve clarity: ellipses indicate omitted text and square brackets indicate author's additions or alterations to text. 
250 Approval was obtained from the Harper Adams University Research Ethics Committee for the

251 collection and storage of interview data. Participants were provided with researcher contact

252 details, project information, and made aware that they could withdraw from the study at any

253 time. Written consent was obtained from participants for interviews to be audio recorded,

254 transcribed and for these data files to be securely stored. Participants also agreed for

255 anonymised interview excerpts to be used when reporting findings.

\section{Results}

258 Average interview length was 56 minutes (range 26 - 90 minutes). Interview extracts regarding colostrum were arranged into two main sub-themes: management practices and obstacles to good colostrum management. These themes include viewpoints and experiences reflective of the sample diversity in this study.

\section{Colostrum management practices}

264 The way in which colostrum management was conducted on farms varied according to personal beliefs and knowledge regarding colostrum and recommended management practices. This theme focuses on the experiences of farmers in the context of their differing farm settings, with some advisor perspectives on the impact of colostrum management to calf health and farmers' understanding of the subject.

All participants, regardless of occupation, recognised the importance of colostrum in calf rearing. Every farmer interviewed named colostrum as one of the most important factors in rearing healthy calves: you don't have the problems" (calf rearer, F6 (organic)). 
275 Although farmers may not associate colostrum management with mortality, they often recognised potential impacts on growth and morbidity in calves:

"If a calf hasn't had its colostrum it inevitably gets a case of some sort of scour, or a lack of motivation to drink. That certainly slows them down at the start. I think they can get through it, but it just doesn't give them the best start" (farm manager, F19).

Participants were familiar with 'The Three 'Q's' of colostrum management which refer to the need for high 'Quality colostrum of sufficient 'Quantity' to be fed to calves 'Quickly' after birth. Advisors used these terms when advising farmers, for example, a pharmaceutical company advisor (PR1) gave talks to farmer groups which included "the 'Three ' $Q$ 's' of colostrum which I bang on about [mention] all the time". These recommendations were generally recognised and acknowledged by farmers, but were implemented to varying degrees, as outlined below.

Colostrum intake within the first 24 hours of a calf's life was a priority and efforts were made to provide calves with two to four litres of colostrum within six hours of birth. Many participants provided additional colostrum feeds, aiming to provide at least six litres of colostrum within six, 12 or 18 hours of birth:

"We don't weigh the calves at all during the process, so the amount of colostrum that they get is always three litres at each feed. Trying to get the first one obviously within six hours and then the second one as soon after as possible, and then we can sometimes get a third in within the first 24 hours" (farm manager, F9).

Some participants perceived value in feeding colostrum or transition milk for several days after birth and believed this practice improved calf vigour:

"People say to me, "Why do you carry on feeding colostrum for two, three days?" Alright, it's not being absorbed in the same way, but it is giving local protection, plus I think giving a smaller amount to those calves and it's higher energy density in that colostrum. So that's why I like it and they seem to do really well" (calf rearer, F2). 
Whereas farmers aimed to feed calves quickly after birth, using stored colostrum from Johne'sfree cows which had been refrigerated or frozen, less focus was placed upon milking the dam as soon after parturition as possible. This appeared largely due to the practicalities of harvesting colostrum outside of routine milking times:

"We try and milk them as soon as they've calved, usually though the parlour at milking ... but if one calves in the middle of the night, or in the late afternoon-evening, then we'll just milk her the following morning" (farm manager, F5).

The method of feeding colostrum to calves largely depended on the time available to staff and the perceived benefits of available options: leaving calves to suckle the dam, or hand feeding via artificial teat or oesophageal tube. Organic farmers in particular left the calf with the dam to suckle colostrum, but admitted calves often required assistance to consume sufficient colostrum: "I usually draw the teats out just to make sure because we dry them off with [teat sealant], and sometimes it's quite difficult for the calf to get out, so you think it's sucking but it's not" (calf rearer F6 (organic)). "[The calves are] left with the cow for 24 to 48 hours, but we make sure they've had enough colostrum. If necessary, we will tube them ... Usually it's just a case of getting them to suck the colostrum off the cow and give it a bottle. If they're sucking well and they won't take any colostrum from a bottle then that's fine" (farm manager, F14 (organic)).

Veterinarian V8 recalled a farm with high calf mortality where calves were not artificially fed colostrum, and that may have contributed to severe failure of passive transfer: "I did zinc sulphate turbidity testing on calves ... a result of 20 [ZST Units] or more is deemed to indicate adequate colostrum, but the highest result I got on that farm was four. That was the highest one and they calved in individual calving boxes and left the calf with the cow for two days."

Stomach tubing was generally used for efficiency on larger or block calving units dealing with high numbers of newborn calves: 
"It's much quicker. You know that the colostrum goes where it wants to go and you know exactly how much they get" (calf rearer, F26).

332 Although artificial teat feeding (via nipple bottle or bucket) was considered a time-consuming practice, farmers often preferred to allow calves to suck; tube feeding was used as a last resort for calves that would not suckle. This seemed due to perceptions of improved calf health and easier training onto teated milk feeders, which could save time in the future:

Whereas farmers were largely concerned with how calves were fed, advisors were more focused on the results of the practices used rather than method itself, per se. In accordance with general recommendations, advisors supported artificial feeding methods, with little preference between oesophageal tube or teat feeding. Their main focus was that calves were acquiring adequate passive transfer from colostrum: 
"I don't mind whether you've chosen to go nipple sucking off buckets ... or [tube] it. As long as you're getting the results and your calves are doing well then that's fine" (youngstock veterinarian, V11).

Advisors and some farmers appreciated the value of monitoring colostrum quality using a colostrometer or refractometer before storing or feeding to calves: "I used to just look at colostrum and go "Oh, that looks fine, feed that to the calf" and now that I've started measuring it ... the amount of colostrum I actually throw away because it's under [19\% on the Brix scale] is amazing! I think we really have seen the benefits now" (calf rearer, F1).

Other farmers were less convinced of the need to quantify colostrum quality and would judge by eye, or use justifications including parity of the dam, breed or average milk components to support claims that colostrum quality was satisfactory: "You can just tell from how it looks, how it feels ... I thought the colostrometer measures the viscosity, how thick it is. So I just thought you would be able to tell that anyway ... Generally from the older cows you get the kind of frothy, thick colostrum ... from heifers it's very thin, and I guess it doesn't have all the antibodies" (calf rearer and farm worker, F3).

"Our average butterfat, 12 months, is 4.5 and 3.4 protein - we're not white water. So I would say our colostrum is probably better than the average" (farm manager, F15).

Generally, collecting the colostrum from different cows together was considered beneficial by farmers to enhance the quality of poorer colostrum:

"The good thing with us, all our colostrum from all our cows goes into that [container]. So it's all mixed up, so some of the cows that have got very high colostrum and say a heifer that hasn't got a lot, it compensates" (calf rearer and farm worker, F23 (organic)). A veterinarian (V7) had a negative view of her clients' knowledge of colostrum quality and suggested that Johne's management was often conflated with colostrum protocols: 

Johne's status, so aren't feeding Johne's colostrum, but that's probably as far as most of them are going".

386 Hygiene was considered an important factor in calf management overall but was not often mentioned specifically in relation to colostrum by farmers, but was stressed by advisors. Several farmers mentioned other farms enacting negative practice where colostrum was left for several hours at ambient temperature in uncovered buckets. However, a common attitude amongst farmers was "we don't have any Johne's problems, so we don't pasteurise [colostrum]" (farm manager, F9), with apparent lack of recognition of the role of pasteurisation in reducing bacterial load in colostrum.

Many farmer interviewees stored colostrum on-farm, either by freezing or refrigerating; advisors did not comment on colostrum storage specifically. Farmers considered it important to ensure colostrum from Johne's-positive dams was not fed to replacement heifer calves, although some would risk infecting bull and beef calves:

Reluctance to use heifer colostrum due to its assumed poorer quality and discarding colostrum as part of Johne's disease control programmes sometimes led to insufficient colostrum being available for storage. Some participants lamented that whilst they monitored colostrum quality they sometimes had to make-do with poorer quality colostrum, or use powdered calf colostrum replacer as an alternative: "We don't save any colostrum from anything that's got Johne's and a lot of time heifers don't give sufficient, if any, colostrum. So if I started discarding colostrum that was of a lower quality in terms of antibodies, I wouldn't have enough to give all the calves" (calf rearer and farm manager, F7) 
"We actually use powdered colostrum. We have done a lot of tests on colostrum levels at a week old on calves that have just been fed the powdered stuff and we have found that the powdered stuff we use is pretty good. It's not as perfect as the mum's, but we've kind of proved that it works because there's lots out there that are [useless]" (calf rearer, F18).

\section{Obstacles to good colostrum management}

This theme explores the challenges farmers perceive regarding colostrum management, reasons behind a failure to follow recommendations, and the perceived role of advisors in supporting farmers to implement best practice and overcome difficulties.

Farmer participants appreciated that good colostrum management could improve passive transfer rates and health status of calves, but these views may not reflect the dairy sector overall. Advisors and some farmers expressed concern that colostrum management was not done well on many farms. Maintenance of traditional practices, age profile and educational attainment were suggested as possible issues:

"Colostrum can be [neglected]. Farmers are getting better ... but you still go on farm and find farmers where they leave the calf with the cow and expect it to find [colostrum] itself. It worked years ago, and it worked well, but we face a whole different host of challenges these days than they did 20 or 30 years ago" (calf nutritionist, N2). "I'm surprised by the number of older farmers that don't know the value of colostrum ... I don't think it's through not being bothered, I think it's through genuine ignorance of not knowing the importance. I think education must've changed a lot between then and now because everybody my age [20-30 years] knows that [colostrum is] of extreme importance" (herd manager, F22).

Colostrum provision for bull and beef calves may also be less of a priority on dairy farms, as the focus is on rearing replacement heifers: 
"If they calve in the middle of the night, [my boss] tends to go on the theory if it's a heifer, he will feed it colostrum that night. If it's a bull calf or a beef, he'll leave it for me and I get in at six [o'clock]" (calf rearer, F18).

Whilst all participating farmers considered colostrum provision to be important, some lacked the knowledge and confidence to alter their practices, or misinterpreted science-based advice,

leading to uncertainty about the reasons behind recommended colostrum management:

"It's just something I know I'm not very good at. I'd like to learn more about it to be honest with you. Taking a calf away from its mother when she's got colostrum there and ... giving it colostrum that you've pooled. I'd want to be confident that I was doing it right" (farm manager, F19).

Calf rearer and farm worker: "Why do you ask [how quickly we refrigerate colostrum]? Interviewer: "Bacteria will grow faster at room temperature than in the fridge" ... Calf rearer and farm worker: "You want some bacteria though, don't you?" (F12).

Others were aware of recommendations, but were disinclined to adhere to them. This may be due to personal preferences, complacency, or negative attitudes towards change and the effort required to implement advice:

"There's always gonna be arguments for everything, isn't there, different ways, but [on the dam is] how [calves] were meant to be, so it's nice for them" (calf rearer and farm worker, F23 (organic)).

"Any colostrum I have left [from freshly calved cows at morning milking] is in the bucket now, so anything that calves between now and milking tonight, I will feed that. Everybody says 'Oh, you shouldn't do that because it's not fresh enough, you should freeze it and then warm it'. Well yeah, you should do lots of things" (calf rearer, F14 (organic)). 
The effectiveness of colostrum management could be hindered by physical limitations, for example the shortage of colostrum for storage mentioned previously. Further challenges included available time, labour and financial considerations. These barriers were commonly mentioned by advisors as reasons for poor colostrum management. There was general consensus among all stakeholders that the work required to run a farm demanded time and labour which were in short supply, and this could impact on the speed of colostrum administration: "I think on dairy farms, one of the big issues is labour. You can't determine when a cow's gonna calve, and of course you want a calf to get colostrum within six or eight hours ... everyone's busy on dairy farms. There's just less and less labour, less and less good stock people on farms" (veterinarian, V10).

Farmers agreed that good colostrum management was time consuming. Most designated calf rearers seemed to cope well with the demands on their time, but those who were also responsible for additional farm work struggled to balance their tasks:

"Colostrum is the hardest thing to do. You've got to be always prepared to take milk out of the freezer and then defrost it, but that's hard to do if I'm milking or something" (calf rearer and farm worker F3).

Calves born at night often were left unfed for longer, largely due to the lack of available staff, and this was often considered unfortunate but unavoidable. Often staff responsible for overnight checks for calvings would not include a designated calf rearer (who was likely to be more invested in the calves), and feeding colostrum at night was not prioritised as a standard practice: "[A cow] might calve at midnight. I don't get down there until eight o'clock the next morning ... They say it needs colostrum within six hours ... That's just how it is, you're not living on the site, it's just one of those things" (calf rearer, F14 (organic)). "If we've got a particularly weak [calf] that we think needs a bit of a perk up, we will feed it during the night ... If you get here and one's just calved and there's another one that needs looking at in half an hour's time ... we'll just [tube feed colostrum to] that calf while we've got five minutes" (farm manager, F13). 
This suggests that 'available labour' is not purely a physical limitation, and personal attitudes and beliefs also play a role. Veterinarian V11 stressed the importance of motivating all relevant staff members to work as a team and take ownership of tasks, like colostrum management, which do not clearly fit into their remit:

"A problem with some of these bigger [farms] is that the cows are somebody else's problem, and the calves are somebody else's, so colostrum falls in-between ... That can be particularly difficult when you're working with different groups of people and they quite like the fact that a big job falls between the gap, then it's nobody's fault".

Having clearly defined roles for each farm team was considered useful by farm manager F26:

"The calf arrives in the calf shed having been through its colostrum policy. That isn't done by us, that's done by the dairy team."

Available finance was also partially reliant upon the perceived worth of an investment. Potential benefits gained must be considered worth the expenditure and be viewed as important compared to other demands for funds:

If farmers were able to see positive results of their actions or investments, they seemed pleased that the decision proved to be cost-effective. Some farmers had invested in a pasteuriser and considered it beneficial both in terms of making their job easier and improving calf health: "We used to put it in the bucket and nearly scorch the outside of the colostrum and the inside would still be frozen whereas now we use the actual pasteuriser which thaws it at the right temperature, all slowly done but within a quick way" (calf rearer, F1). "As soon as we've put [the pasteuriser] in, we're certainly getting a lot less scour in the calves, so that's been a good investment" (farm manager, F21). 
This apparent need for changes to have tangible benefits may help to explain why advisors claimed that farmers would usually wait until a problem presented itself before implementing colostrum protocols. Some farmer participants confirmed that improvements were made in response to problems:

"Often we put in protocols where they would deliver stomach tube, bottle, teat or bag to make sure the calf has had [colostrum], but that would usually follow a problem. If it's all working, why fix it?" (veterinarian, V8).

"I've known us to have some real problems, and as soon as we got that colostrum sorted, that didn't half tick a lot of boxes" (farm manager, F21).

However, testing calf serum to monitor rates of passive transfer did not appear to be conducted by many participant farms. Only two farmers (F18, F24) reported routine testing of calves, and four (F4, F6, F20, F21) mentioned testing calves in response to problems. This lack of quantification could make it difficult to identify problems which need addressing, or assess the benefits of any alterations. Further incentives or checks for good colostrum management may be beneficial, with one farm manager (F20) suggesting an accreditation scheme for colostrum management in calves may better encourage best practice:

"Guarantee that the calf has had the correct amount of colostrum and it gets a stamp on the passport. When it goes to market it shows up 'accredited', but it could be checked at any point, blood tested to see if it's had the right antibodies ... Adding value to the supply chain, isn't it? Should be part of farm assurance, really".

Advisors were frustrated at the lack of objective data to base recommendations on, but were sympathetic to the difficulties in enacting recommendations on-farm. Recognising that time and labour were limited, they stressed the need to ensure advice was easy to implement. Youngstock veterinarian V11 warned against over-simplification of advice and claimed that compromises could be made when following recommendations while still achieving good results: "To achieve [calves receiving four litres of colostrum within four hours of birth] on a small herd with limited labour is really tough ... It's not quite as simple as just that, 
which I think a lot of vets before have gone "Oh, just do this" and walked off ... It's always a balance, if you've got your timings right, and it's clean, and the other 'Q's are ticked, then you can get away with giving a bit less volume."

However, advisors may not seize opportunities to demonstrate recommended practices to farmers, as illustrated by this quote from a farm manager: nice and yellow, and looks nice and thick""' (farm manager, F15).

Furthermore, farmers may not recognise the root cause of problems, and rely upon the expertise of advisors. However, a calf nutritionist (N2) attributed blame to veterinarians overlooking the role of colostrum management in calf health problems:

Such oversights on colostrum management can prove costly and may contribute to high mortality rates and overuse of antimicrobials: "I took over the work on a 450 cow dairy and the first thing the farmer said is "You

\section{Discussion}

573 As has been demonstrated in studies such as Robinson (2017) and Adam et al (2017), it is important to understand the context within which farmers operate, and the various intrinsic and extrinsic influences that may affect their attitudes and behaviours in relation to livestock health. 
The themes explored in the current study demonstrate a heterogeneous group of both farmers and farm advisors whose individual perspectives, experiences and contexts impact their actions and recommendations relating to colostrum management. Appreciating this diversity is important for achieving a holistic understanding of calf health and welfare at farm level. Indeed, the opinions of farm advisors such as livestock nutritionists rarely feature in the animal health and welfare literature, and these important perspectives need to be included in future research studies.

Farmer and advisor interviewees agreed that colostrum intake is of great importance for calf rearing, and key to giving calves "the best start". Participants appreciated that good colostrum management could prevent problems in calves, but focused on the importance of antibodies in colostrum rather than other beneficial factors (eg hormones and growth factors (Blum \& Hammon 2000)). Although all participants recognised the importance of colostrum and its role in calf health, it does not necessarily follow that farmers follow best practice or that advisors focus on or suggest improvements to colostrum management. Efforts to administer colostrum to bull and beef calves were likely to be lax; these animals are not destined to become dairy herd replacements (although beef heifer calves may join suckler herds) and may have low market value (Weigel \& Barlass 2003). Even regarding potential replacement heifers, the general consensus between participants was that colostrum management in the overall dairy industry was better than it had been historically, but standards could be further improved. Recent recommendations include the five 'Q's of colostrum management (Hart 2016), but the majority of advice and scientific literature focuses on 'The Three 'Q's ' (Patel et al 2014; AHDB Dairy 2018). No participants in the current study, including advisors, referred to five 'Q's, but knowledge of 'The Three 'Q's' was commonplace among farmers and advisors. However, some interviewees mentioned less-informed farmers and several participants appeared to require clarity about the reasoning behind recommendations. 
603 Even where recommendations were understood, achieving each 'Q' could be challenging. The

604 recommendation to feed equivalent to $10 \%$ of a calf's bodyweight in colostrum is of limited use;

605 calves are rarely weighed (Hart 2016) and farmers in this study more often quoted

606 recommended values of 3-4 L. Farmers were aware that calves required at least one colostrum

607 feed within six hours of birth, but achieving this could be difficult: some farms only harvested

608 colostrum at routine milking times, which delayed its collection following calving, and time and

609 labour limitations were apparent. This is consistent with previous findings where time pressures

610 and prioritisation of the milking herd negatively impacted the speed of colostrum administration

611 to newborn calves (Santman-Berends et al 2014). In the present study, calf rearers with clearly

612 defined roles, mainly pertaining to calf care, had more time designated to calves; they could

613 focus on calf requirements and consider the benefits of good colostrum management. Staff

614 having the time to carry out their tasks and respond to unforeseen problems is fundamental to

615 good animal husbandry: time management, control and perceived self-efficacy have been found

616 to influence the severity of calf mortality on farms (Vaarst \& Sørensen 2009). However, staff

617 structure, labour costs, calving pattern and calf numbers can make a designated calf rearer an

618 unrealistic solution on many farms. In particular, night-time calvings often resulted in delayed

619 colostrum administration; either night checks were conducted by staff who were not involved in

620 calf rearing and focused on assisting calving, or not conducted at all. This highlights the

621 importance of ensuring the entire farm team is motivated to engage with calves, and consider

622 their management worth investing time and money into, as stressed by youngstock veterinarian

623 V11. Indeed, Vasseur et al (2010b) found that encouraging active participation in training and

624 learning new methods was a good way to stimulate farmers to improve their colostrum

625 management practices.

627 Farmers' attitudes, motivations and doubts are important considerations when offering guidance 628 and can strengthen tailored advice (Santman-Berends et al 2014). Farmers have been shown to 629 perceive targeted advice, including explanations for recommended measures, as useful (Vasseur 630 et al 2010b) and whilst tailored approaches are more likely to prompt implementation (Vasseur 
et al 2010b; Santman-Berends et al 2014), they did not guarantee improvements to colostrum

632 practices within six months (Vasseur et al 2010b). This could suggest that some farmers are

633 slow or reluctant to adapt existing practices (Santman-Berends et al 2014), or that improved

634 understanding alone is insufficient motivation to make or maintain changes. In the current

635 study, feeding method was chosen according to perceived benefits or drawbacks rather than

636 basing decisions on evidence-based recommendations. Decisions were based on ease, time,

637 suitability for the farm system, and sometimes veterinary advice. A herd's Johne's status often

638 influenced feeding practices due to controls against infecting calves (Windsor \& Whittington

639 2010). One farmer was concerned that he might enact snatch calving incorrectly, so continued to

640 leave calves to suckle their dam. This reluctance to replace one suboptimal protocol with

641 another is understandable. Doubts could be eased with improved encouragement, guidance in

642 amending established systems or practices, and reassurance that alterations would have positive

643 effects.

645 Several organic farmers in the current study believed leaving calves to suckle colostrum from

646 their mother was natural and therefore beneficial. The concept of 'naturalness' is a key aspect of

647 organic farming (Vetouli et al 2010), and research indicates that cow-calf contact can encourage

648 appropriate social behaviours of calves (Buchli et al 2017). However, this practice increases the

649 risk of failure of passive transfer (McGuirk \& Collins 2004), so farm staff should feed

650 colostrum to calves (Patel et al 2014). There were also negative perceptions of recommended

651 practices; for example, one farming couple had ethical objections over oesophageal tube-feeding

652 of colostrum as standard practice, believing that public perception would be negative. When

653 done correctly, stomach-tubing is generally considered a safe method (Besser et al 1991; Kaske

654 et al 2005), and immunoglobulin transfer is comparable to teat feeding (Besser et al 1991;

655 Chigerwe et al 2012). However, calves sometimes resist swallowing the tube and incorrect

656 procedure could result in aspiration (Chigerwe et al 2012), injuries to the pharynx and

657 potentially fatal drenching pneumonia (Kaske et al 2005). These findings indicate tube-feeding 
may be an unpleasant experience for calves, and warrant further investigation into its effects on calf welfare.

660

661 Advisors indicated most clients knew very little about their colostrum quality and claimed withholding colostrum from Johne's-positive dams was considered sufficient by some farmers. All farmer participants appreciated that colostrum quality related to its immunoglobulin content, but bacterial contamination was less of a concern. There was some evidence of misinterpretation or incomplete knowledge or understanding of scientific findings. For example, one farmer participant conflated the role of bacteria in acquired immunity with the cleanliness of colostrum, similar to farmers believing disease exposure to be a protective biosecurity measure (Brennan et al 2016; Frössling \& Nöremark 2016). Other farmer participants considered the benefits of pasteurisation to be limited to the prevention of Johne's disease. However, pasteurising colostrum has been shown to reduce its bacterial load and can reduce pathogen exposure to newborn calves (Elizondo-Salazar et al 2010). This emphasises the importance of extending 'The Three 'Q's' to include hygiene as a specific recommendation.

Whilst participants who assessed colostrum quality using a colostrometer or Brix refractometer considered it a useful practice, one farmer used 19\% (Brix) as a cut-off point which given that the recommendation is that colostrum should have a Brix reading of $22 \%$ or higher, could mean less than one third of poor quality samples are correctly identified (Bartier et al 2015). Some farmers used poorer quality colostrum to alleviate colostrum shortages. Other farmers assumed it was an unnecessary bother; they believed immunoglobulin content of colostrum could be adequately judged according to its viscosity and colour. Safeguards were implemented eg withholding colostrum from primiparous dams, though this practice may be unnecessary and wasteful as heifer colostrum can be of high quality (Godden 2008) and seemed to contribute to colostrum shortages on some farms. Pooling colostrum from multiple dams was often considered beneficial but high-quality colostrum is actually diluted by larger volumes of low immunoglobulin content colostrum (Weaver et al 2000). Colour measurement via 
spectrophotometry has indicated that colostrum with a more yellow and darker colour is likely to contain higher levels of immunoglobulin and constituents which contribute to the nutritive value of colostrum (Gross et al 2014). However, it is unlikely that judging colostrum by eye provides reliable and accurate indication of quality compared to recommended implements. Though colostrometers have been criticised for their fragility and temperature dependency, Brix refractometers function independently of temperature and are user-friendly, requiring a very small amount of colostrum to sample (Bartier et al 2015), but still add another step to the colostrum management routine. A lack of enthusiasm to quantify measures has been reported in other areas concerning cattle health and welfare, eg farmers in one study did not believe mobility scoring would improve their ability to identify cases of lameness (Horseman et al 2014). This suggests farmers will monitor and implement recording practices only when they perceive some benefit or reward for doing so, regardless of best practice advice. This is somewhat paradoxical, as limited data can hinder the assessment of the risk or reward associated with management practices.

Some advisor interviewees claimed that farmers would usually improve their colostrum management only in response to a recognised health problem. Similar attitudes have been found in research concerning biosecurity and vaccination - farmers will often react to a problem rather than taking preventive action (Richens et al 2015; Brennan et al 2016). This tendency for reactivity as opposed to proactivity could relate to limited time and labour - why put effort into changing practices that are apparently functional? Sub-standard record keeping by farmers (Escobar 2015), particularly concerning calves (Bach \& Ahedo 2008), prevents evidence-based, objective assessment of calf health and welfare issues before they present themselves as noticeable and concerning problems. Producers who participated in a benchmarking program for failure of passive transfer and average daily gain in milk-fed calves were motivated to alter management practices to improve calf performance (Atkinson et al 2017). However, very few

712 of the participants interviewed in our study tested calves to monitor passive transfer and 713 subsequent performance. For optimal evaluation of serum total protein or IgG concentrations, 
714 blood samples must be taken within the first week of a calf's life, and timing should be

715 consistent to allow comparison (Villarroel et al 2013). This may be difficult to achieve, and cost

716 of testing can deter farmers, but Brix refractometers, in addition to testing colostrum quality,

717 can be used as an inexpensive estimate of calf serum immunoglobulin (Deelen et al 2014).

718 Achieving adequate transfer of immunity is the ultimate goal, regardless of which practices are

719 used, so convincing farmers to adhere to the fifth 'Q' of colostrum management - quantification

720 of passive transfer - is of great importance.

721

722 Lack of calf monitoring data may also partly explain why few participant farmers mentioned the 723 economic significance of colostrum management, and why most downplayed the importance of 724 colostrum administration in preventing calf mortality. One farmer suggested testing calves for 725 adequate passive transfer as part of an accreditation scheme or farm assurance, but such 726 approaches may not be highly motivating to farmers (Leach et al 2010). Farm advisors could 727 potentially better highlight the avoidable cost of failure of passive transfer and aid decision728 making using the method described by Raboisson et al (2016). The ongoing benefits of good colostrum management could also be better promoted. For example, calves with adequate 730 passive transfer require fewer antimicrobial treatments (Berge et al 2009). In this vein, the

731 Responsible Use of Medicines in Agriculture (RUMA) Alliance recently launched the '\#ColostrumIsGold' campaign which promotes the role of colostrum management in reducing antibiotic usage on-farm (www.colostrumisgold.org).

The current study indicated that calf mortality and morbidity could be wrongly attributed to disease challenge rather than failure of passive transfer. Advisors could prompt farmers to reevaluate their assessment of such problems, but our findings suggest some veterinarians do not examine colostrum management when investigating calf issues. One farmer mentioned that his veterinarian did not challenge his tendency to assess colostrum quality by eye. This could be

740 because some recommendations are not considered worthwhile to dispute if farmers are 741 perceived as likely to continue using methods despite advice to the contrary. In such cases, 
providing visual assessment criteria to guide farmers' judgement might be beneficial, but this

743 should be done alongside recommending best practice, possibly by demonstrating use of a colostrometer or Brix refractometer. Veterinarians are key advisors to farmers (Elliott et al 2011; Garforth et al 2013) so it is important that they provide a comprehensive and competent service which promotes science-based recommendations. It cannot be assumed that limited uptake of evidence-based advice is solely due to lack of engagement by farmers.

Interviews were a useful method to gain insight into participants' perspectives on colostrum management. Findings are indicative of what the wider dairy farmer population in England may believe or practice, but further research is needed to establish statistical representation. The first author was responsible for all interviews, transcription and coding which could introduce researcher bias and a tendency for invalid interpretations of participants' perspectives (Miles et al 2014). To protect descriptive validity, verbatim transcriptions were made from audio recordings of the interviews and the selection and editing of presented quotes did not distort what was actually said. However, it was necessary to infer meaning from the words of participants who may distort or conceal their views or recall experiences inaccurately (Maxwell 2012). To encourage honest, open discussion of calf rearing issues, interviews were conducted in a non-judgemental manner and participants chose their preferred interview format (seated, mobile or joint).

A range of participants were recruited. Farm managers, herd managers and calf rearers working on farms of varying sizes provided insight into the perspectives and priorities of those with different responsibilities and schedules. Advisors were knowledgeable about dairy youngstock and able to provide informative accounts of calf rearing based on their experiences. That fewer advisors participated in the project than farmers is not a concern since no statistical comparisons were made, but these interviews were valuable in triangulating the data obtained from the farmers, and also in exploring the wider context to colostrum management that we aimed for in the study. Due to farm-specific variations eg in calving pattern, herd size, staff structure and 
finances, the point of thematic saturation required a greater number of interviews for farmers than for advisors. All interview formats yielded useful insights into calf rearing but mobile and joint interviews were particularly informative. Mobile interviews enhanced farm-specific discussion since the researcher could view buildings, equipment and animals whilst participants reflected on their day-to-day practices (Holton \& Riley 2014). Joint interviews allowed for conarration which provided details and reflection on shared experiences which would have been unattainable by the interviewer alone (Riley 2014). Interviews specifically designed to investigate one particular aspect of calf rearing eg colostrum management would have allowed for more probing questions to generate more detailed data on that topic (Weller et al 2018). However, the goal of the present research was to explore the broad topic of dairy calf rearing so the emergent theme of colostrum management could not have been pre-empted.

\section{Animal welfare implications and conclusion}

Our study demonstrates that 'The Three 'Q's' acted as useful reminders about the goals of colostrum management. It is possible that greater dissemination of 'The Five 'Q's', which include hygiene and monitoring of passive transfer as specific criteria, could further increase awareness of those important aspects. Knowledge of the 'Q's of colostrum management did not guarantee implementation of recommended protocols. To motivate action to reduce failure of passive transfer rates in calves, advice should consider: physical challenges including Johne's management and time constraints; misconceptions, eg about the role of pathogens in acquired immunity; and farmers' perceptions, priorities and preferences. The welfare implications of oesophageal tube feeding may need further investigation if it is to be recommended as standard

Quantification of passive transfer, when considered alongside health, growth and performance data, could help convince farmers that improved colostrum management merits the investment of more time, labour and finance. However, most farmers were reluctant to record and analyse 
data, so different motivational tactics to encourage long-term monitoring should be trialled.

Advisors must not overlook the critical importance of colostrum management when investigating calf health issues and should promote the use of evidence-based recommendations in the farm context when advising farmers on dairy calf health and welfare.

\section{Acknowledgements}

The authors would like to thank the Barham Benevolent Foundation for funding this project. We are most grateful for the help of participating farmers and advisors in the interviews, and those who assisted in publicising the research. We would also like to thank the journal editor for their consideration of this paper for publication and very much appreciate the valuable input from our reviewers.

\section{References}

Adam CJM, Ducrot CPM, Paul MC and Fortané N 2017 Autonomy under contract: the case of traditional free-range poultry farmers. Review of Agricultural, Food Environmental Studies 98: 55-74.

AHDB Dairy 2018 Calf Management. Available online at: https://dairy.ahdb.org.uk/technicalinformation/youngstock/\#.XMwbl6TTWUk

Atkinson DJ, von Keyserlingk MAG and Weary DM 2017 Benchmarking passive transfer of immunity and growth in dairy calves. Journal of Dairy Science 100: 3773-3782.

Bach A and Ahedo J 2008 Record keeping and economics of dairy heifers. Veterinary Clinics of North America - Food Animal Practice 24: 117-138.

Bartier AL, Windeyer MC and Doepel L 2015 Evaluation of on-farm tools for colostrum quality measurement. Journal of Dairy Science 98: 1878-1884.

\section{Beam AL, Lombard JE, Kopral CA, Garber LP, Winter AL, Hicks JA and Schlater JL} 2009 Prevalence of failure of passive transfer of immunity in newborn heifer calves and associated management practices on US dairy operations. Journal of Dairy Science 92: 3973-3980.

Berge ACB, Besser TE, Moore DA and Sischo WM 2009 Evaluation of the effects of oral colostrum supplementation during the first fourteen days on the health and performance of preweaned calves. Journal of Dairy Science 92: 286-295. 
Besser TE, Gay CC and Pritchett L 1991 Comparison of three methods of feeding colostrum to dairy calves. Journal of the American Veterinary Medical Association 198: 419-422.

Blum JW 2003 Colostrum - More than just an immunoglobulin supplier. Acta Veterinaria Scandinavica 44: 123-124.

Bourély C, Fortané N, Calavas D, Leblond A and Gay E 2018 Why do veterinarians ask for antimicrobial susceptibility testing? A qualitative study exploring determinants and evaluating the impact of antibiotic reduction policy. Preventive Veterinary Medicine 159: 123-134.

Bradley EH, Curry LA and Devers KJ 2007 Qualitative Data Analysis for Health Services Research: Developing Taxonomy, Themes, and Theory. Health Services Research 42: $1758-1772$.

Braun V and Clarke V 2006 Using thematic analysis in psychology. Qualitative Research in Psychology 3: 77-101.

Brennan ML, Wright N, Wapenaar W, Jarratt S, Hobson-West P, Richens IF, Kaler J, Buchanan H, Huxley JN and O'Connor HM 2016 Exploring Attitudes and Beliefs towards Implementing Cattle Disease Prevention and Control Measures: A Qualitative Study with Dairy Farmers in Great Britain. Animals 6: 61.

Buchli C, Raselli A, Bruckmaier R and Hillmann E 2017 Contact with cows during the young age increases social competence and lowers the cardiac stress reaction in dairy calves. Applied Animal Behaviour Science 187: 1-7.

Chigerwe M, Coons DM and Hagey J V 2012 Comparison of colostrum feeding by nipple bottle versus oroesophageal tubing in Holstein dairy bull calves. Journal of the American Veterinary Medical Association 241: 104-109.

Cohen L, Manion L and Morrison K 2007 Research Methods in Education, 6th Edition. Routledge, London.

Cuttance EL, Mason WA, Laven RA, McDermott J and Phyn CVC 2017 Prevalence and calf-level risk factors for failure of passive transfer in dairy calves in New Zealand. New Zealand Veterinary Journal 65: 297-304.

Deelen SM, Ollivett TL, Haines DM and Leslie KE 2014 Evaluation of a Brix refractometer to estimate serum immunoglobulin $\mathrm{G}$ concentration in neonatal dairy calves. Journal of Dairy Science 97: 3838-3844.

DeNise SK, Robison JD, Stott GH and Armstrong D V 1989 Effects of Passive Immunity on Subsequent Production in Dairy Heifers. Journal of Dairy Science 72: 552-554.

Elizondo-Salazar JA, Jayarao BM and Heinrichs AJ 2010 Effect of heat treatment of bovine colostrum on bacterial counts, viscosity, and immunoglobulin $\mathrm{G}$ concentration. Journal of Dairy Science 93: 961-967.

Ellingsen K, Mejdell CM, Hansen B, Grøndahl AM, Henriksen BIFF and Vaarst M 2012 Veterinarians' and agricultural advisors' perception of calf health and welfare in organic dairy production in Norway. Organic Agriculture 2: 67-77. 
Elliott J, Sneddon J, Lee JA and Blache D 2011 Producers have a positive attitude toward improving lamb survival rates but may be influenced by enterprise factors and perceptions of control. Livestock Science 140: 103-110.

Escobar MP 2015 Perceptions and practices of farm record-keeping and their implications for animal welfare and regulation. Defra, London.

Escobar MP and Buller H 2014 Projecting Social Science into Defra's Animal Welfare Evidence Base: A review of current research and evidence gaps on the issue of farmer behaviour with respect to animal welfare. Defra, London.

Frössling J and Nöremark M 2016 Differing perceptions - Swedish farmers' views of infectious disease control. Veterinary Medicine and Science 2: 54-68.

Garforth CJ, Bailey AP and Tranter RB 2013 Farmers' attitudes to disease risk management in England: A comparative analysis of sheep and pig farmers. Preventive Veterinary Medicine 110: 456-466.

Glaser BG and Strauss AL 1967 The Discovery of Grounded Theory: Strategies for Qualitative Research. Aldine, Piscataway, New Jersey

Godden S 2008 Colostrum Management for Dairy Calves. Veterinary Clinics of North America - Food Animal Practice 24: 19-39.

Gross JJ, Kessler EC and Bruckmaier RM 2014 Colour measurement of colostrum for estimation of colostral IgG and colostrum composition in dairy cows. Journal of Dairy Research 81: 440-444.

Hart K 2016 Colostrum quality. Livestock 21: 288-290.

Holton M and Riley M 2014 Talking on the move: place-based interviewing with undergraduate students. Area 46: 59-65.

Horseman S, Roe E, Huxley J, Bell N, Mason C and Whay H 2014 The use of in-depth interviews to understand the process of treating lame dairy cows from the farmers' perspective. Animal Welfare 23: 157-165.

Kaske M, Werner A, Schuberth HJ, Rehage J and Kehler W 2005 Colostrum management in calves: Effects of drenching vs. bottle feeding. Journal of Animal Physiology and Animal Nutrition 89: 151-157.

Kehoe SI, Jayarao BM and Heinrichs AJ 2007 A Survey of Bovine Colostrum Composition and Colostrum Management Practices on Pennsylvania Dairy Farms. Journal of Dairy Science 90: 4108-4116.

Leach KA, Whay HR, Maggs CM, Barker ZE, Paul ES, Bell AK and Main DCJ 2010 Working towards a reduction in cattle lameness: 2. Understanding dairy farmers' motivations. Research in Veterinary Science 89: 318-323.

Macfarlane JA, Grove-White DH, Royal MD and Smith RF 2015 Identification and quantification of factors affecting neonatal immunological transfer in dairy calves in the UK. Veterinary Record 176: 625. 
Maxwell JA 2012 A Realist Approach for Qualitative Research. Sage Publications, Thousand Oaks, California.

McGuirk SM and Collins M 2004 Managing the production, storage, and delivery of colostrum. Veterinary Clinics of North America - Food Animal Practice 20: 593-603.

Miles MB, Huberman AM and Saldana J 2014 Qualitative Data Analysis: A Methods Sourcebook, 3rd edition. Sage Publications, Thousand Oaks, California.

Moore M, Tyler JW, Chigerwe M, Dawes ME and Middleton JR 2005 Effect of delayed colostrum collection on colostral IgG concentration in dairy cows. Journal of the American Veterinary Medical Association 226: 1375-1377.

Morrill KM, Conrad E, Lago A, Campbell J, Quigley J and Tyler H 2012 Nationwide evaluation of quality and composition of colostrum on dairy farms in the United States. Journal of Dairy Science 95: 3997-4005.

Patel S, Gibbons J and Wathes DC 2014 Ensuring optimal colostrum transfer to newborn dairy calves. Cattle Practice 22: 95-104.

Raboisson D, Trillat P and Cahuzac C 2016 Failure of Passive Immune Transfer in Calves: A Meta-Analysis on the Consequences and Assessment of the Economic Impact. PLoS ONE 11: $\mathrm{e} 0150452$.

\section{Richens IF, Hobson-West P, Brennan ML, Lowton R, Kaler J and Wapenaar W 2015} Farmers' perception of the role of veterinary surgeons in vaccination strategies on British dairy farms. Veterinary Record 177: 465.

Riley M 2014 Interviewing fathers and sons together: Exploring the potential of joint interviews for research on family farms. Journal of Rural Studies 36: 237-246.

Robinson PA 2017 Farmers and bovine tuberculosis: Contextualising statutory disease control within everyday farming lives. Journal of Rural Studies 55: 168-180.

Robinson PA 2019 Performativity and a microbe: Exploring Mycobacterium bovis and the political ecologies of bovine tuberculosis. BioSocieties 14: 179-204.

Robinson PA and Epperson WB 2013 Farm animal practitioners' views on their use and expectations of veterinary diagnostic laboratories. Veterinary Record 172: 503.

Robison JD, Stott GH, DeNise SK 1988 Effects of passive immunity on growth and survival in the dairy heifer. Journal of Dairy Science 71:1283-1287.

Rose G 1997 Situating knowledges: positionality, reflexivities and other tactics. Human Geography 21: 305-320.

Santman-Berends IMGA, Buddiger M, Smolenaars AJG, Steuten CDM, Roos CAJ, Van Erp AJM and Van Schaik G 2014 A multidisciplinary approach to determine factors associated with calf rearing practices and calf mortality in dairy herds. Preventive Veterinary Medicine 117: 375-387.

Smith T and Little RB 1922 The significance of colostrum to the new-born calf. Journal of Experimental Medicine 36: 181-198. 
Sumner CL and von Keyserlingk MAG 2018 Canadian dairy cattle veterinarian perspectives on calf welfare. Journal of Dairy Science 101:10303-10316.

Sumner CL, von Keyserlingk MAG and Weary DM 2018 How benchmarking motivates farmers to improve dairy calf management. Journal of Dairy Science 101: 3323-3333.

Turner DW 2010 Qualitative Interview Design: A Practical Guide for Novice Investigators. The Qualitative Report 15: 754-760.

Vaarst M and Sørensen JT 2009 Danish dairy farmers' perceptions and attitudes related to calf-management in situations of high versus no calf mortality. Preventive Veterinary Medicine 89: 128-133.

Vasseur E, Borderas F, Cue RI, Lefebvre D, Pellerin D, Rushen J, Wade KM and de Passillé AM 2010a A survey of dairy calf management practices in Canada that affect animal welfare. Journal of dairy science 93: 1307-1315.

Vasseur E, Rushen J, de Passillé a M, Lefebvre D and Pellerin D 2010b An advisory tool to improve management practices affecting calf and heifer welfare on dairy farms. Journal of dairy science 93: 4414-4426.

Vetouli T, Lund V and Kaufmann B 2012 Farmers' attitude towards animal welfare aspects and their practice in organic dairy calf rearing: A case study in selected Nordic farms. Journal of Agricultural and Environmental Ethics 25: 349-364.

Villarroel A, Miller TB, Johnson ED, Noyes KR and Ward JK 2013 Factors affecting serum total protein and immunoglobulin $\mathrm{G}$ concentration in replacement dairy calves. Advances in Dairy Research 01: 106.

Weaver DM, Tyler JW, VanMetre DC, Hostetler DE and Barrington GM 2000 Passive transfer of colostral immunoglobulins in calves. Journal of Veterinary Internal Medicine 14: 569-577.

Weigel KA and Barlass KA 2003 Results of a producer survey regarding crossbreeding on US dairy farms. Journal of Dairy Science 86: 4148-4154.

Weller SC, Vickers B, Bernard HR, Blackburn AM, Borgatti S, Gravlee CC and Johnson JC 2018 Open-ended interview questions and saturation. PLOS ONE 13: e0198606.

Whay HR 2007 The journey to animal welfare improvement. Animal Welfare 16: 117-122.

Windsor PA and Whittington RJ 2010 Evidence for age susceptibility of cattle to Johne's disease. The Veterinary Journal 184: 37-44.

Wittum TE and Perino LJ 1995 Passive immune status at postpartum hour 24 and long-term health and performance of calves. American Journal of Veterinary Research 56: 1149_ 1154. 